\title{
First Characterization of the Ultra-Shielded Chamber in the Low-noise Underground Laboratory (LSBB) of Rustrel Pays d'Apt
}

\author{
G. Waysand ${ }^{1,4, *}$, D. Bloyet ${ }^{2}$, J.P. Bongiraud ${ }^{3}$, J.I. Collar ${ }^{1,4}$, C. Dolabdjian ${ }^{2}$, Ph. Le Thiec ${ }^{3}$ \\ ${ }^{1}$ Groupe de Physique des Solides (UMR CNRS 75-88), Universités Paris 6 83 7, 2 Pl. Jussieu, Paris 75251, France \\ ${ }^{2}$ Groupe de Recherche en Informatique, Image et Instrumentation de Caen ISMRA, Université de Caen, 14050 Caen, France \\ ${ }^{3}$ Laboratoire de Magnétisme du Navire, ENSEIG/INPG, Université Joseph Fourier, 38 Grenoble, France \\ ${ }^{4}$ Laboratoire Souterrain à Bas Bruit (LSBB) de Rustrel-Pays d'Apt, 84400 Rustrel, France
}

\begin{abstract}
In compliance with international agreements on nuclear weapons limitation, the French groundbased nuclear arsenal has been decommissioned in its totality. One of its former underground missile control centers, located in Rustrel, $60 \mathrm{~km}$ east of Avignon (Provence) has been converted into the "Laboratoire Souterrain à Bas Bruit de Rustrel-Pays d'Apt" (LSBB). The deepest experimental hall ( $500 \mathrm{~m}$ of calcite rock overburden) includes a $100 \mathrm{~m}^{2}$ area of sturdy flooring suspended by and resting on shock absorbers, entirely enclosed in a $28 \mathrm{~m}$-long, $8 \mathrm{~m}$-diameter, $1 \mathrm{~cm}$-thick steel Faraday cage. This results in an unparalleled combination of shielding against cosmic rays, acoustic, seismic and electromagnetic noise, which can be exploited for rare event searches using ultra low-temperature and superconducting detectors. The first characterization measurements in this unique civilian site are reported. http://www.gps.jussieu.fr/RUSTREL/rustrel.html
\end{abstract}

*E-mail: waysand@gps.jussieu.fr

\section{Description of the infrastructure}

Rustrel, a small village in the Pays d'Apt, is one hour by car east of Avignon, in the heart of Provence (southeast France). The high-speed train connection from Paris to Avignon takes three hours and twenty minutes. Marseille-Marignagne is the nearest international airport, one hour and a half from Rustrel. The village is just south of the Plateau d'Albion, the former location for the ground-based component of the French air force's "force de frappe" (strike force). The military selection of this location was presumably due to the proximity of the eastern French border, low density of population, good rock quality, and the existence of mountains offering natural protection. Missile silos were spread over a large area, with two underground launching centers on both sides of the Mount Ventoux.

One of these centers has been spared from destruction and is now converted into a laboratory (LSBB); the usable spare parts and technical subsystems from the second center have been preserved for future maintenance of the LSBB. The LSBB consists of $3.2 \mathrm{~km}$ of reinforced concrete galleries below the "Grande Montagne" (1,010 $\mathrm{m}$ at the summit), joining various halls. An heliport is available in front of the entrance area, which houses office space and living quarters. A telecommunications area in the summit is directly connected via optical fiber to the deepest part of the galleries, the launching control room.

Two major experimental halls are available; the shallowest ( $350 \mathrm{~m}^{2}, 7 \mathrm{~m}$ ceiling height, $50 \mathrm{~m}$ rock overburden) is located 400 meters from the entrance and is shielded in the same manner as the launching control room (one kilometer further down the corridors, protected by $500 \mathrm{~m}$ of calcite rock). This control room is the second hall of 
interest and includes $100 \mathrm{~m}^{2}$ of sturdy flooring suspended by shock absorbers. The room is entirely surrounded by a horizontal steel capsule $28 \mathrm{~m}$-long, $8 \mathrm{~m}$ in diameter and $1 \mathrm{~cm}$-thick; entrance doors are clamped by electrical contacts to ensure the sealing of this peculiar Faraday cage. Several auxiliary galleries at the same depth can be used for experiments not needing exceptional EM shielding.

Due to its previous purpose, the whole setup was designed to offer maximum safety against intrusion and nuclear attack: External and internal steel doors can bear 20 bars of overpressure and emergency generators respond in a tenth of a second to energy supply perturbations. Ten optical fibers are available for telecommunications with the exterior. The whole area is fully airconditioned, with ventilation and running water reaching the deepest hall. Road traffic is very scarce within two kilometers from the laboratory.

\section{Radiation shielding \& natural radioactivity}

\subsection{Neutrons}

The capsule and surrounding rooms are located at a depth of $\sim 1,500$ meters of water equivalent (m.w.e.). In this sense, LSBB ranks about average when compared to other underground laboratories. Nevertheless, this depth is more than enough to ensure screening of secondary cosmic neutrons (fig. 1). Indeed, neutrons produced by natural radioactivity in the surrounding rocks are dominant below few hundreds of m.w.e., independent of the nature of the shielding materials used in the experiments (deeply-reaching muons can produce neutrons in this shielding). An increased depth brings no further reduction in neutron flux [1].

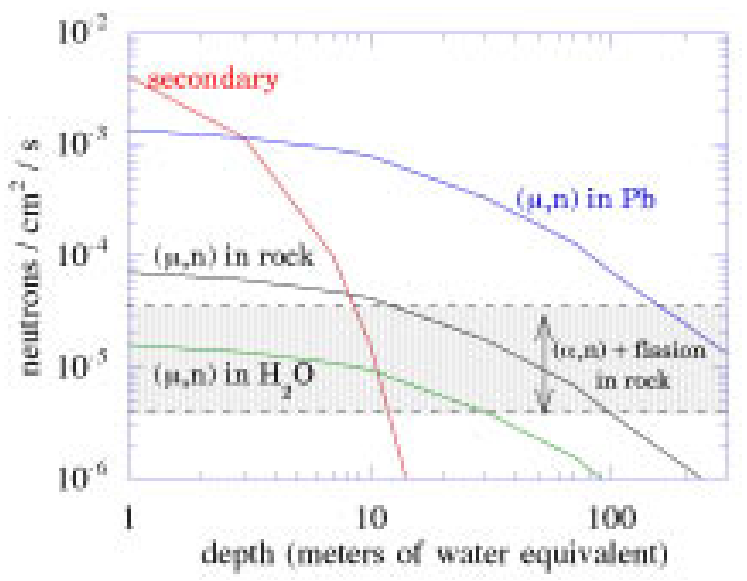


FIG. 1. Components of neutron flux as a function of underground depth. The greyed band covers the typical contribution from natural radioactivity in rocks, based on large-depth measurements and the average $\mathrm{U}$ and $\mathrm{Th}$ concentration in the Earth's crust. The contribution to the flux from muon interactions is derived from the systematics and measurements of [2] (similar results are obtained in [3]).

\subsection{Muons}

At 1,500 m.w.e. the muon flux becomes a second order concern for most of the activities envisioned at LSBB, and can be further suppressed by anticoincidence with an active veto (plastic scintillator) without creating a substantial dead time. In the case of ultra-low temperature experiments, long-lived heating by passing muons (a problem at ground level) is a rare occurrence at a flux of $\sim 5 \cdot 10^{-3} \mu / m^{2} / s$ (fig. 2).

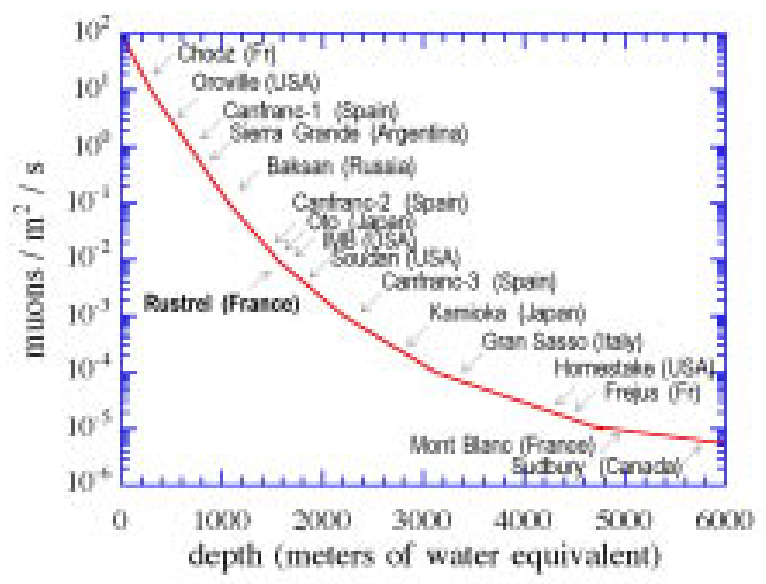

FIG. 2. Muon flux as a function of depth for several underground laboratories [4].

\subsection{Rock radioactivity}

Rock samples were extracted from exposed walls in secondary galleries, measured by the CERN radioprotection service and compared with a reference calcite rock from a low-depth gallery nearby Paris. Only two isotopes were detected above background (table 1).

\begin{tabular}{lll}
\hline Isotope & $\begin{array}{l}\text { Boissise la Bertrand } \\
\text { (Seine et Marne) }\end{array}$ & $\begin{array}{l}\text { LSBB } \\
\text { (Rustrel) }\end{array}$ \\
${ }^{137} \mathrm{Cs}$ & $0.204 \mathrm{~Bq}$ & $0.437 \mathrm{~Bq}$ \\
${ }^{226} \mathrm{Ra}$ & $2.030 \mathrm{~Bq}$ & $0.645 \mathrm{~Bq}$ \\
\hline
\end{tabular}

Table 1: Identifiable rock radioactivity in Boissise (near Paris), and in the Laboratoire Souterrain à Bas Bruit (LSBB).

Comparable levels were found, within the factor 2 uncertainty in the activities. While this is nowhere close to an exhaustive measurement, it allows to discard the 
possibility that Rustrel rock might be unusually "hot".

\subsection{Airborne radon}

The radon concentration in the atmosphere of the capsule was measured during three weeks in January 1998 using a RAD7 NITON radonmeter (a self-contained continuousmonitoring solid state alpha detector [5]). An average value of $28 \mathrm{~Bq} / \mathrm{m}^{3}(0.77 \mathrm{pCi} / \mathrm{l})$ was obtained [6]. As a reference, this can be compared with the maximum acceptable $45 \mathrm{~Bq} / \mathrm{m}^{3}$ in US households, or with the lowest values achieved in the Gran Sasso underground laboratory, $20-50 \mathrm{~Bq} / \mathrm{m}^{3}$ [7]. Similar results have been obtained in April 1999. This low rate, comparable to outdoor measurements in the area, is a factor 15 lower than during military operation. The improvement was obtained by opening the vertical escape chimney of the site, allowing for natural ventilation, and by turning off a cooling unit within the capsule. The escape chimney was normally obstructed for security reasons; as a result, in spite of the strong ventilation in the gallery, the deepest hall was almost a dead end for air circulation.

\section{Seismicity and acoustic noise}

The area of Rustrel is well-studied from a geological point of view. It is at the center of a $30 \mathrm{~km}$ circle free of active faults in spite of the relative proximity to the Alps. This structural configuration is the reason for the absence of local seismicity during the last eleven hundred years [8]. The acoustic environmental noise has been roughly characterized in a $20 \mathrm{~m}^{2}$ shielded room adjacent to the capsule during the installation of the SIMPLE experiment [9], which relies precisely on acoustic detection of the weak signal arising from the vaporization of superheated freon droplets suspended in a gel matrix. At the level of sensitivity of our room monitoring microphones, no significant activity was detected after the ventilation ducts were muffled.

\section{Electromagnetic shielding}

\subsection{A unique underground shielding}

The peculiar shielding of the main experimental halls was designed with the intention of protecting electronic equipment from the huge electromagnetic pulse created by a nearby nuclear explosion. This is the reason why, instead of a conventional Faraday cage made of thin copper, the choice was made for a thick $(1 \mathrm{~cm})$ steel shielding. As a result, these large cages attenuate not only highfrequency electromagnetic waves but also low-frequency and even DC (e.g., the magnetic field of the Earth). Due to their large dimensions it is possible to locally create large magnetic fields as long as the walls have not reached their magnetic saturation. In other words, within these cages one can have very low magnetic fluctuations even at non-zero magnetic field values. 


\subsection{DC domain}

The chosen steel was not optimized for magnetic shielding; nevertheless, the residual magnetic field inside the capsule is lower than $6 \mu \mathrm{T}$ (compare with $46 \mu \mathrm{T}$ for the Earth's magnetic field at the LSBB latitude). The measurements were done with triaxial fluxgate magnetometers with a bandwidth from 0 to 5 Hertz, a noise level of $0,5 \mathrm{nT}$ (peak to peak) and an absolute precision of $200 \mathrm{nT}$ $(0.2 \mu \mathrm{T})$. Over a period longer than 12 hours a remarkable long-term stability and low noise level (less than 20 nT) were observed. This performance is not extreme, yet very impressive when observed over such a large experimental area (one would have to wait more than 12 hours to observe, in a square loop of $0.3 \times 0.3 \mathrm{~mm}^{2}$, a magnetic flux variation larger than one quantum flux!). Such a long-term magnetic stability allows for the utilization of SQUID detectors with large pick-up coils. A Hall-effect gaussmeter applied directly on the steel walls just above the welding lines revealed only a weak local magnetization (local magnetic field smaller than $100 \mu \mathrm{T}$ ). At the expense of a few precautions (displacement of the ventilating units, compensated AC wiring) the EM quality of the site can be improved even further.

\subsection{Dynamic fluctuations}

Using a triaxial fluxgate connected to a spectrum analyzer, the performance of the shielding was measured from 1 to $1000 \mathrm{~Hz}$. No detectable signal above the noise level of the measuring chain was obtained, indicating that the magnetic fluctuations are lower than $2.5 \mathrm{pT} / \mathrm{Hz}^{1 / 2}$. Finally, in early August 1999 a high-Tc SQUID was operated for a short period inside the capsule; from this measurement it was concluded that in the same frequency range the noise level is below $600 \mathrm{fT} / \mathrm{Hz}^{1 / 2}$.

\section{Conclusion}

This first set of characterization measurements indicates that a singular combination of shielding features makes of LSBB a site of choice for low-noise experiments in the fields of ultra-low temperature physics, superconductivity, biology, metrology and astroparticle physics.

Acknowledgements: We are indebted to M. Auguste, G. Boyer, A. Cavaillou and L. Ibtiouene for their help in performing these measurements.

[1] J.I. Collar, T.A. Girard, D. Limagne and G. Waysand, Procs. of the 1st International Workshop on the Identification of Dark Matter (IDM96), Sheffield, U.K., 
1996. N.Spooner ed., World Scientific (Singapore) astro-ph/9610266.

[2] G.V. Gorshov et al., Sov. J. Nucl. Phys. 13 (1971) 450.

[3] G. Heusser, Nucl. Instr. Meth A369 (1996) 539.

[4] A.Morales, Inaugural Lecture of the 95-96 academic year, Universidad de Zaragoza.

[5] Niton electronics, P.O. Box 368, Bedford MA 01730, USA.

[6] http://www.gps.jussieu.fr/RUSTREL/radon. JPG

[7] C. Arpesella et al., Health Phys. 72 (1997) 629.

[8] B. Grellet, Ph. Combes and D. Carbon, Geo-Ter Laboratory, Université de Montpellier: Procs. of the 1997 meeting of the ANDRA (French national agency for nuclear waste), Bagnols-sur-Cèze, 20-21 October 1997. Published by ANDRA.

[9] J.I. Collar, T.A. Girard, D. Limagne, H.S. Miley, J. Puibasset and G. Waysand, Procs. of the 2nd Intl. Workshop on the Identification of Dark Matter (IDM98), Buxton, U.K., 1998. N.Spooner ed., World Scientific (Singapore); http://taup99.in2p3.fr/cgi-bin/taup/ get_scan.pl?Monday+workshop+J_Collar. 